\title{
Perancangan Sistem Informasi Aplikasi Tracer Study Alumni Berbasis Website
}

\author{
Rizal Bagus Pambudi, Agung Triayudi", Andrianingsih \\ Fakultas Teknologi Komunikasi dan Informatika, Informatika, Universitas Nasional, Jakarta, Indonesia \\ Email: ${ }^{1}$ rizalbagus71@ gmail.com, 2," agungtriayudi@ civitas.unas.ac.id, ${ }^{3}$ andrianingsih.mrs@ gmail.com \\ Email Penulis Korespondensi: agungtriayudi@civitas.unas.ac.id
}

\begin{abstract}
Abstrak-Tracer Study merupakan studi yang dilakukan perguruan tinggi untuk melakukan pencarian alumni yang mempunyai tujuan untuk mengetahui timbal balik pendidikan alumni dalam dunia kerja. Universitas nasional sendiri sudah mempunyai website tracer study tapi masih kesulitan dalam melaksanakan tracer study, terutama untuk menghubungi alumni. Metode yang digunakan dalam penelitian ini menggunakan metode waterfall yang terstruktur. Dalam hal ini, tahapan awal yang dilakukan untuk metode ini adalah melakukan observasi yang bertujuan mencari dan mengetahui permasalahan yang dihadapi oleh user serta melakukan pengumpulan data dengan cara melakukan pencarian studi literatur yang berhubungan dengan tracer study berbasis website hingga melakukan testing sistem pengujian website menggunakan blackbox yaitu pengujian terhadap kebutuhan fungsi dari setiap menu pada suatu program. Penelitian ini menghasilkan aplikasi sistem tracer study berbasis website yang memudahkan alumni untuk melakukan proses tracer study yang dapat dilakukan kapanpun dan dimanapun. Hasil dari tracer study sendiri akan menjadi tolak ukur universitas dalam mengembangkan kemampuan mahasiswa kedepannya agar dapat bersaing di dunia kerja.
\end{abstract}

Kata Kunci: Tracer Study, Perguruan tinggi, Website, Metode Waterfall, Blackbox testing

Abstract-Tracer Study is a study conducted by tertiary institutions to search for alumni whose purpose is to find out the reciprocal of alumni education in the world of work. National universities themselves already have a tracer study website but still have difficulty in carrying out tracer studies, especially to contact alumni. The method used in this study uses a structured waterfall method. In this case, the initial stage for this method is to make observations that aim to find and find out the problems faced by users and to collect data by searching literature studies related to website-based tracer studies to testing website testing systems using blackboxes, namely testing the function requirements of each menu in a program. This research resulted in the application of a website-based tracer study system that facilitates alumni to carry out the tracer study process which can be done anytime and anywhere. The results of the tracer study itself will serve as a benchmark for the university in developing the ability of future students to compete in the workforce.

Keywords: Tracer Study, College, Website, Method Waterfall, Blackbox

\section{PENDAHULUAN}

Perguruan tinggi merupakan bagian yang sangat penting sebagai salah satu ruang pendidikan nasional yang mempunyai tanggung jawab dalam hal mendidik generasi penerus bangsa untuk menjadikan bangsa ini lebih baik kedepannya. Salah satu caranya yaitu dengan mewujudkan pendidikan yang memiliki kualitas dan bermanfaat secara langsung terhadap masyarakat [1]. Untuk mencapai tujuan tersebut maka pihak perguruan tinggi harus memperbaiki kualitas alumninya.

Salah satu cara mewujudkan pendidikan yang memiliki kualitas alumni adalah pendidikan berbasis kompetensi. Cara tersebut menunjukkan bahwa pendidikan yang dilaksanakan harus sesuai dengan kebutuhan dunia kerja, sehingga keterserapan lulusan oleh dunia kerja menjadi tinggi.[2] Seberapa besar lulusan perguruan tinggi mampu berkiprah dalam pembangunan sesuai relevansi pendidikannya dapat dilakukan upaya penelusuran terhadap lulusannya (Tracer Study) [3].

Tracer study atau yang sering disebut sebagai survey alumni atau survey "follow up" adalah studi mengenai lulusan dari suatu lembaga penyelenggara pendidikan tinggi. Studi ini mampu menyediakan berbagai informasi yang bermanfaat bagi kepentingan evaluasi hasil pendidikan tinggi dan selanjutnya dapat digunakan untuk penyempurnaan dan penjaminan kualitas lembaga pendidikan tinggi yang bersangkutan [4].

Tracer Study perlu dilakukan setiap tahunnya agar setiap perguruan tinggi dapat mengevaluasi seberapa lulusannya dapat terserap di dunia kerja sesuai dengan bidang yang ditekuninya. Informasi-informasi yang didapatkan sangat berguna bagi perguruan tinggi untuk membenahi materi pembelajaran yang lebih bermanfaat.[5]

Masalah yang muncul pada penggunaan website pengelolaan tracer study informasi data alumni di universitas nasional belum sepenuhnya diperhatikan dan tidak menarik bagi alumni [6], hal ini dapat menyebabkan terjadinya perlambatan dalam mengikuti perkembangan lingkungan kerja, dan perguruan tinggi membutuhkan respon balik dari alumninya untuk perbaikan sistem dan meningkatkan kualitas pendidikan [7] [8].

Berdasarkan permasalahan diatas dibentuk sebuah sistem rancangan untuk mendapatkan informasi data alumni dengan menggunakan teknologi website.[9] Hasil dari penelitian ini akan menghasilkan suatu perancangan sistem informasi aplikasi tracer study yang dapat ikut membantu mengatasi permasalahan kesenjangan kesempatan kerja dan upaya perbaikannya terhadap alumni yang ada di suatu universitas [10].

Tujuan dari penelitian ini untuk memberikan kemudahan alumni dalam memberikan proses pencarian data alumni dan mengetahui perkembangan alumni serta menyediakan lowongan pekerjaan bagi alumni, dan aspek 
JURNAL MEDIA INFORMATIKA BUDIDARMA

Volume 4, Nomor 3, Juli 2020, Page 642-649

ISSN 2614-5278 (media cetak), ISSN 2548-8368 (media online)

Available Online at https://ejurnal.stmik-budidarma.ac.id/index.php/mib

DOI 10.30865/mib.v4i3.2198

lainnya [11]. Dengan dikembangkannya sistem informasi ini diharapkan dapat membantu dalam mengetahui penyebaran para lulusan di dunia kerja [12]. Dalam aplikasi ini akan dirancang juga tambahan fitur pencarian lowongan pekerjaan agar alumni yang belum memiliki pekerjaan dapat melihat fitur tersebut yang belum ada di website sebelumnya dan dapat digunakan oleh user dengan baik [13].

\section{METODOLOGI PENELITIAN}

\subsection{Metode}

Metode pengembangan sistem yang digunakan yaitu life cycle atau waterfall model.

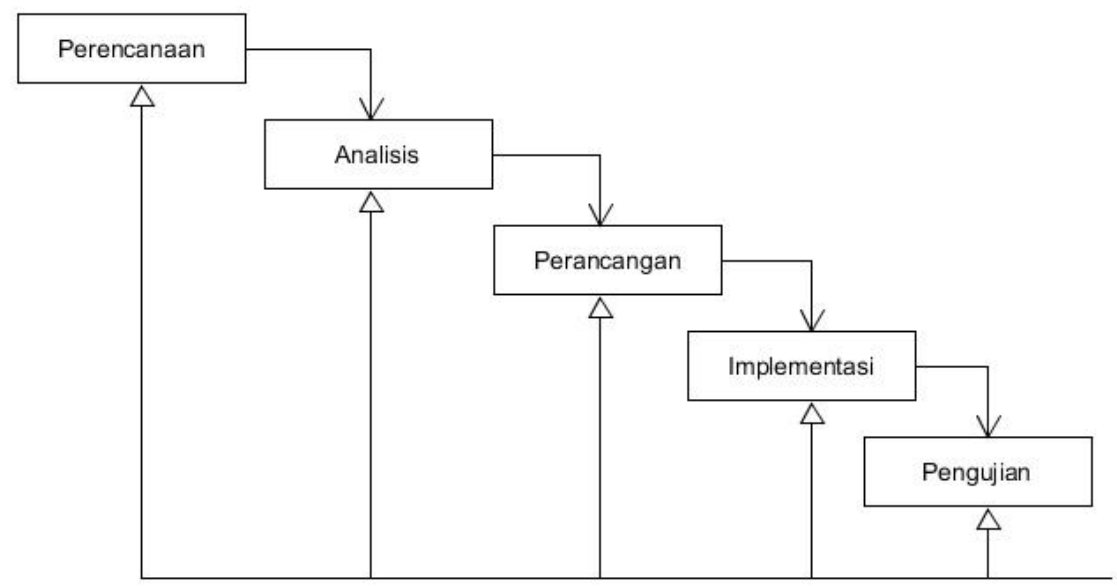

Gambar 1. Tahapan pengembangan metode waterfall

Tahapan pada pengembangan metode waterfall adalah :

1. Perencanaan

Pada tahapan ini bertujuan untuk mengarahkan pengembangan agar sesuai dengan sistem yang akan dibuat, kemudian membatasi apa yang boleh dan tidak boleh dilakukan pada pembuatan sistem.

2. Analisis

Pada tahapan analisis ini bertujuan untuk mendapatkan pemahaman secara keseluruhan tentang testing sistem yang akan dikembangkan berdasarkan masukan dari user. Tujuan dari tahapan ini yaitu menentukan solusi terhadap sistem yang akan dibuat. Hasil dari analisis ini adalah untuk memahami sistem seluruhnya sebagai persiapan ke tahap perancangan(desain).

3. Perancangan

Pada tahapan ini bertujuan untuk menentukan bentuk sistem arsitektur yang memenuhi standar dan batasan teknologi, membuat abstraksi yang tak terlihat pada implementasi sistem. Hasil dari analisis ini merancang sebuah desain website yang responsive.

4. Implementasi

Setelah melalui tahapan diatas, maka sebuah sistem siap dan dapat diimplementasikan. Dalam tahapan implementasi ada beberapa tugas yang dijalankan diantaranya mengimplementasikan desain dalam sebuah komponen source code,script dan tabel, kemudian menyempurnakan arsitektur dan testing system.

5. Pengujian

Setelah melakukan tahapan implementasi, maka terdapat sebuah pengujian atau testing. Pengujian ini dilakukan menggunakan dengan prosedur blackbox.

\subsection{Metode Pengumpulan Data}

Adapun metode untuk pengumpulan data terdiri dari data primer dan sekunder:

a. Data primer

Mengumpulkan data secara langsung dari tempat yang diteliti. Adapun cara yang dipakai untuk mengumpulkan data adalah sebagai berikut.

1. Metode wawancara

Penulis bertanya kepada pegawai dibagian kemahasiswaan universitas nasional. Wawancara dilakukan untuk menemukan kebutuhan apa saja yang ingin dirancang dalam kegiatan tracer study.

2. Metode Observasi

Pada metode ini penulis mengamati secara langsung yang berhubungan dengan permasalahan yang diteliti untuk dianalisa

3. Metode dokumentasi 


\section{JURNAL MEDIA INFORMATIKA BUDIDARMA}

Volume 4, Nomor 3, Juli 2020, Page 642-649

ISSN 2614-5278 (media cetak), ISSN 2548-8368 (media online)

Available Online at https://ejurnal.stmik-budidarma.ac.id/index.php/mib

DOI 10.30865/mib.v4i3.2198

b. Data sekunder

Pada metode ini penulis mendokumentasikan data lapangan sebagai bahan laporan.

Data sekunder diperoleh dengan cara mempelajari buku-buku referensi, artikel, jurnal yang terindeks SINTA dan internet yang dapat dipercaya untuk menjadi bahan acuan penulis selama melakukan penelitian ini.

\section{HASIL DAN PEMBAHASAN}

Pada tahapan ini terdapat hasil analisa, hasil perancangan dan implementasi pengujian website. Tahapan awal untuk saat ini yaitu hasil analisa yang didokumentasikan menggunakan UML(unified model language) yang dilaksanakan terhadap sistem aplikasi tracer study yang sedang dibuat pada penelitian ini.

\subsection{Perancangan UML}

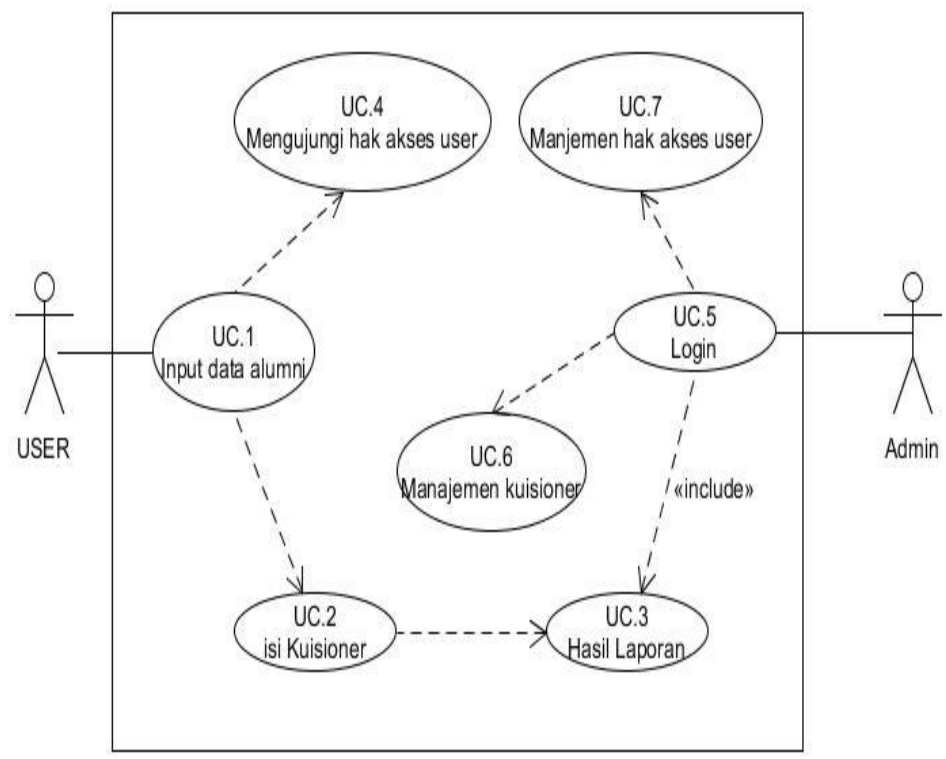

Gambar 2. Use case diagram

Use case diagram tersebut menjelaskan tentang hasil analisa sistem aplikasi tracer study pada penelitian ini. Penjelasan lebih lanjut dijelaskan dalam tabel berikut :

Tabel 1. Keterangan use case diagram

\begin{tabular}{|c|c|c|}
\hline No & Use case & Keterangan \\
\hline UC.1 & Input data alumni & $\begin{array}{l}\text { Use case ini diakses user untuk menginput data alumni } \\
\text { sebelum mengisi kuisioner }\end{array}$ \\
\hline UC. 2 & Isi kuisioner & $\begin{array}{l}\text { Use case ini diakses user yang bertujuan untuk mengisi } \\
\text { kuisioner yang telah dibuat oleh admin }\end{array}$ \\
\hline UC.3 & Hasil Laporan & $\begin{array}{l}\text { Hasil laporan hanya bisa diakses oleh admin, yang } \\
\text { bertujuan untuk melihat hasil kuisioner yang telah diisi } \\
\text { oleh alumni }\end{array}$ \\
\hline UC.4 & Mengunjungi hak akses user & $\begin{array}{l}\text { Use case ini merupakan hak akses user untuk melihat } \\
\text { menu fitur di halaman website seperti : } \\
\text { - } \quad \text { Menu kegiatan } \\
\text { - } \quad \text { Menu galeri }\end{array}$ \\
\hline UC. 5 & Login admin & $\begin{array}{l}\text { Use case ini hanya bisa diakses admin untuk masuk ke } \\
\text { halaman admin. }\end{array}$ \\
\hline UC.6 & Manajemen kuisioner & $\begin{array}{l}\text { Use case ini diakses oleh admin untuk membuat } \\
\text { kuisioner dan menerima hasil kuisioner }\end{array}$ \\
\hline UC.7 & Manajemen hak akses user & $\begin{array}{l}\text { Use case ini diakses oleh admin untuk menambah data, } \\
\text { mengedit, dan menghapus data terkait fitur-fitur seperti } \\
\text { menu kegiatan, menu galeri dan menu lowongan } \\
\text { pekerjaan yang dapat dilihat oleh user. }\end{array}$ \\
\hline
\end{tabular}

Berdasarkan hasil analisa terhadap sistem informasi tracer study, maka setelah itu membuat hasil perancangan sistem untuk mengetahui bagaimana alur activity di setiap sistem yang sedang dibuat. 
ISSN 2614-5278 (media cetak), ISSN 2548-8368 (media online)

Available Online at https://ejurnal.stmik-budidarma.ac.id/index.php/mib DOI $10.30865 /$ mib.v4i3.2198

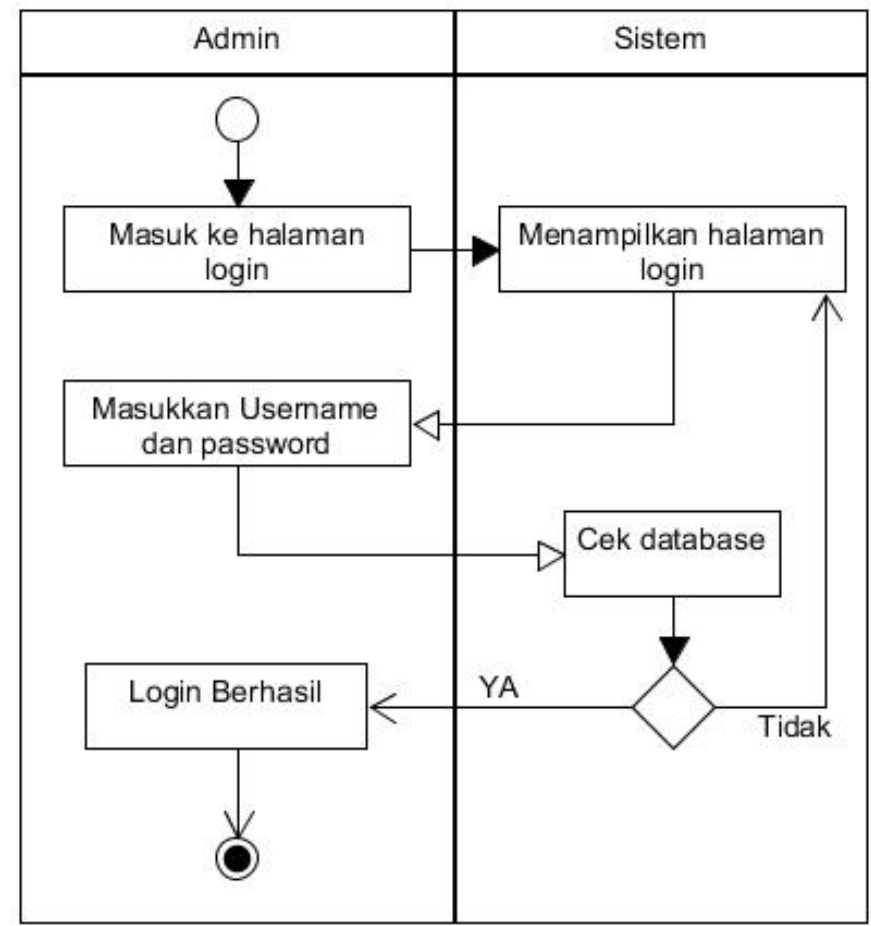

Gambar 3. Activty diagram login admin

Diagram activty login pada gambar 3 merupakan aktivitas yang hanya bisa dilakukan oleh admin. Diagram ini terdiri dari aktifitas menampilkan halaman login yang hanya bisa diakses oleh admin dan kemudian admin mengisi username dan password.

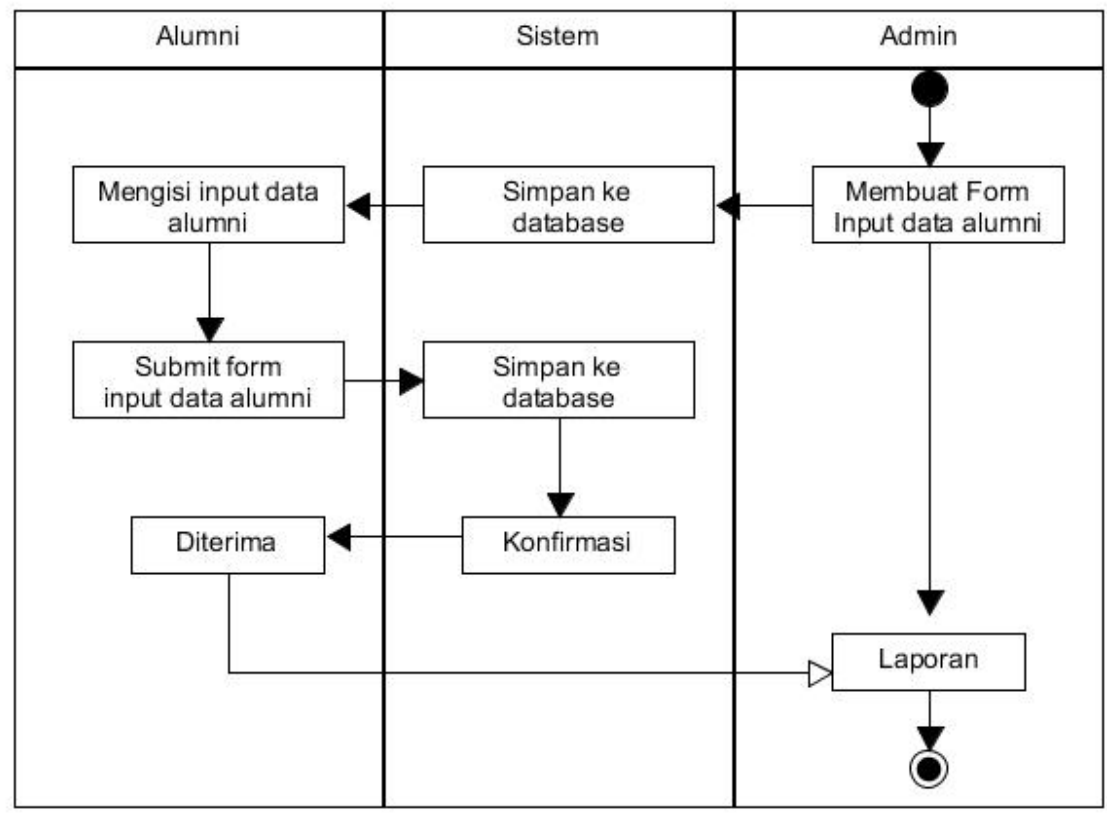

Gambar 4. Activity form input alumni

Diagram activity input alumni pada gambar 4 merupakan aktivitas yang bisa dilakukan oleh user yang dikelola oleh admin. Diagram tersebut terdiri dari aktifitas untuk menampilkan hasil inputan tiap alumni. 
JURNAL MEDIA INFORMATIKA BUDIDARMA

Volume 4, Nomor 3, Juli 2020, Page 642-649

ISSN 2614-5278 (media cetak), ISSN 2548-8368 (media online)

Available Online at https://ejurnal.stmik-budidarma.ac.id/index.php/mib

DOI 10.30865/mib.v4i3.2198

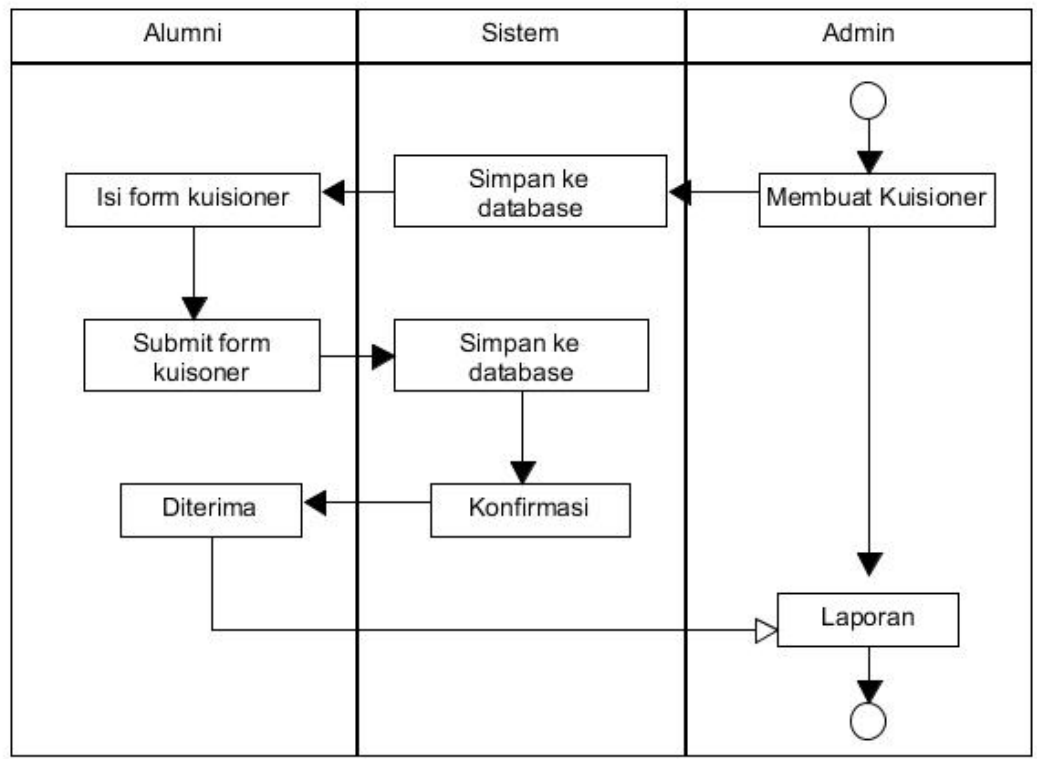

Gambar 5. Activity diagram kuisioner

Diagram activity kuisioner pada gambar 5 merupakan aktivitas yang bisa dilakukan oleh user yang dikelola oleh admin. Diagram tersebut terdiri dari aktifitas untuk menampilkan hasil kuisioner dan menghapus data hasil kuisioner.

\subsection{Perancangan ERD (Entity relationship diagram)}

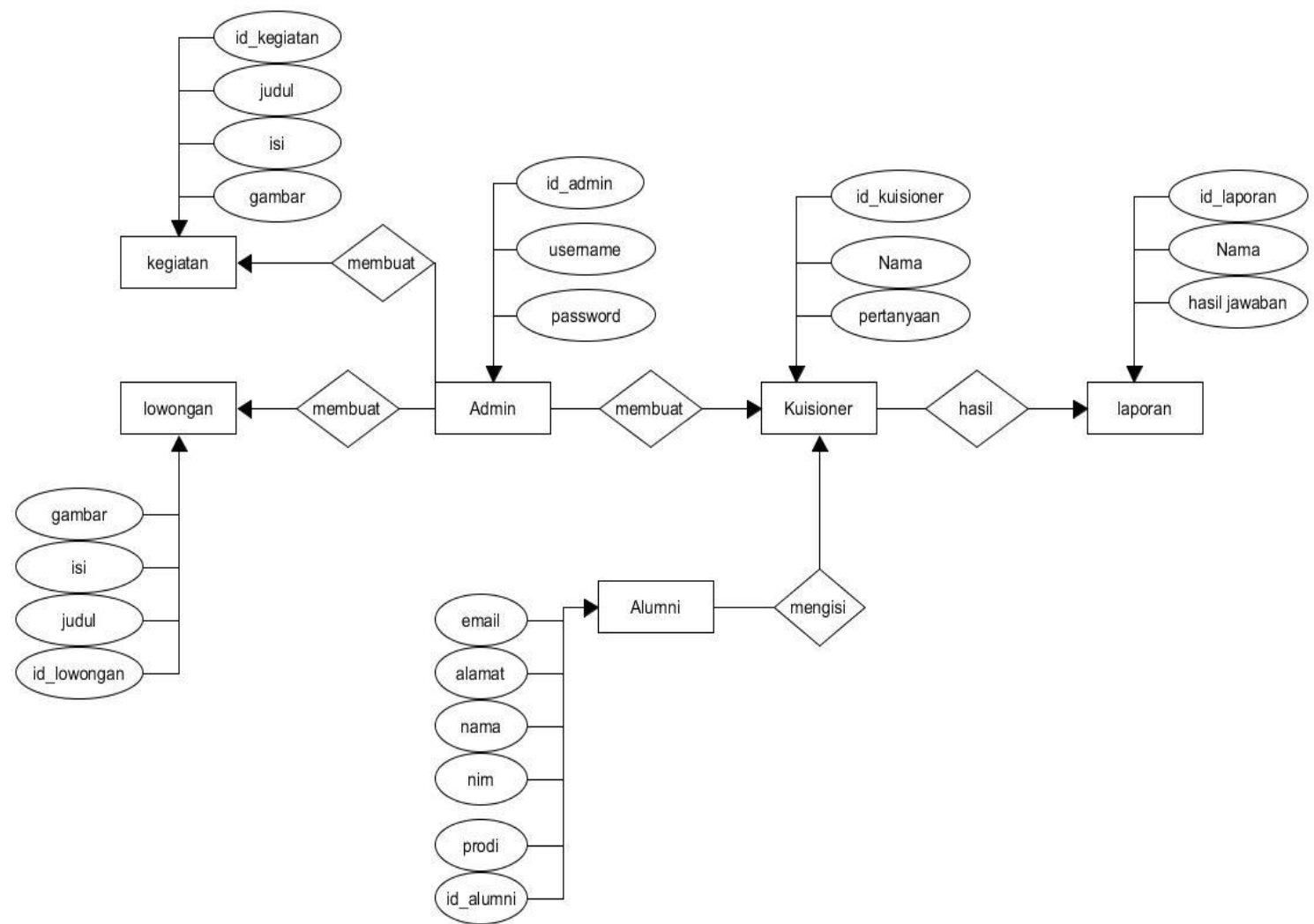

Gambar 6. Entitiy relationship diagram

Pada gambar 6 merupakan entity relationship diagram(ERD) dari sistem aplikasi yang akan dirancang. Dalam ERD sistem ini terdapat 6 tabel yang saling berelasi, yaitu tabel admin, alumni, kuisioner, laporan, kegiatan dan tabel lowongan. Nantinya data-data tersebut dapat dikelola oleh admin dan data alumni dapat dilihat melalui sistem yang akan dirancang. 
JURNAL MEDIA INFORMATIKA BUDIDARMA

Volume 4, Nomor 3, Juli 2020, Page 642-649

ISSN 2614-5278 (media cetak), ISSN 2548-8368 (media online)

Available Online at https://ejurnal.stmik-budidarma.ac.id/index.php/mib

DOI 10.30865/mib.v4i3.2198

\subsection{Perancangan LRS(Logical record structure)}

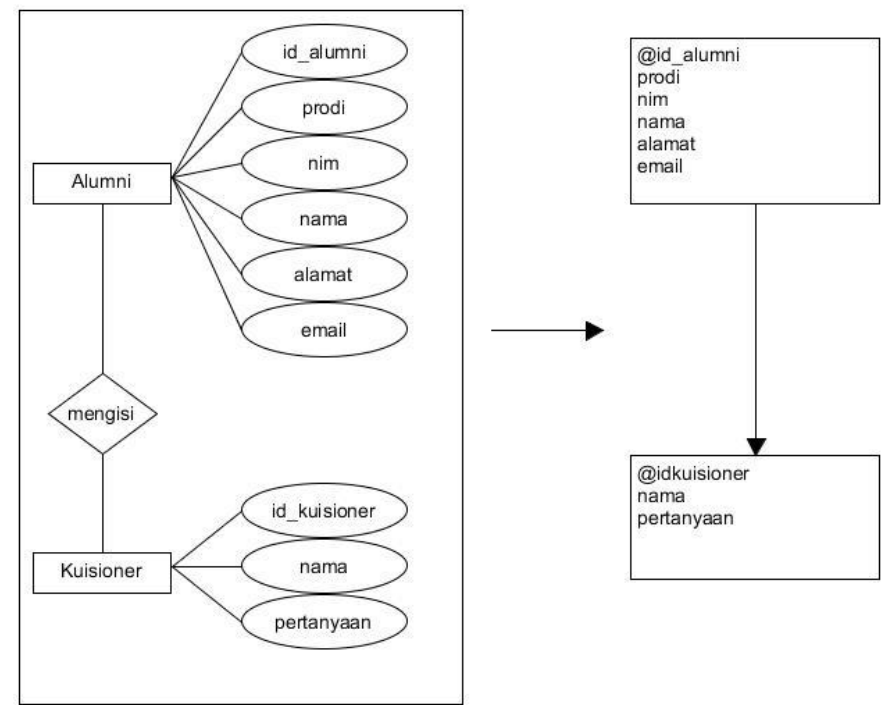

Gambar 7. Logical record structure

Pada gambar 7 merupakan logical record structure pada relasi mengisi, relasi ini menghubungkan antara entity alumni dan entity kuisioner. Pada kasus ini akan diberikan simbol @ untuk primary key pada entity tersebut.

\subsection{Implementasi Website Tracer Study}

Setelah tahapan analisis dan perancangan telah dilakukan, maka tahap selanjutnya adalah tahap implementasi. Pada tahap ini penulis membuat sebuah program dengan hasil sebagai berikut :

\section{a. Halaman utama website}

Halaman utama mempunyai menu utama yang terdiri dari halaman kegiatan, galeri, kuisioner, lowongan pekerjaan dan halaman about.

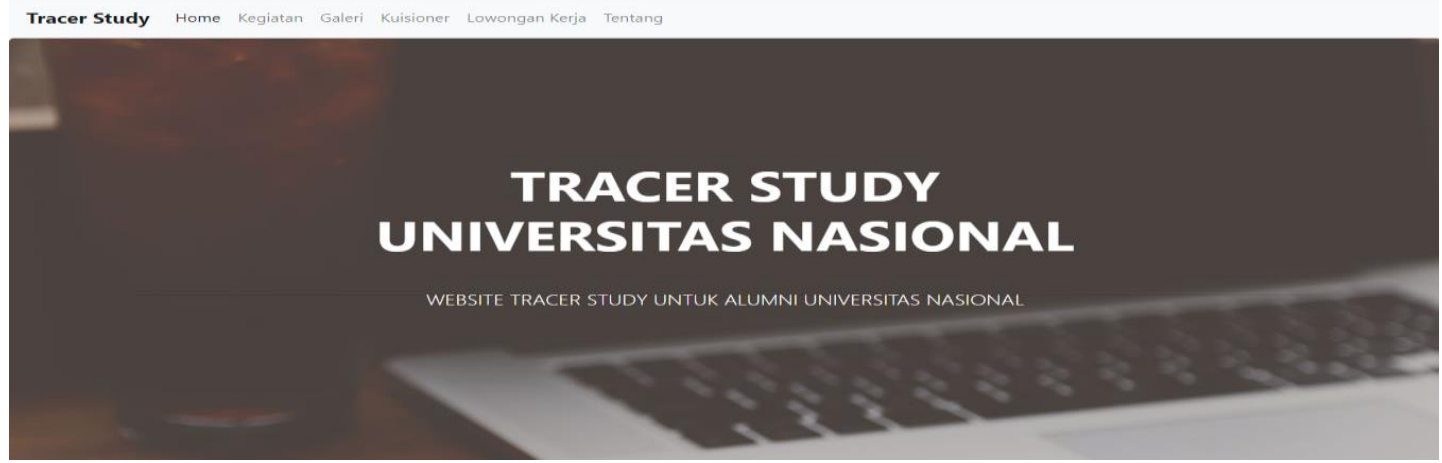

b. Halaman login admin

Gambar 8. Halaman utama website

Untuk halaman login admin hanya bisa diakses oleh admin dan akses user dibatasi disini.

\section{Login Page}

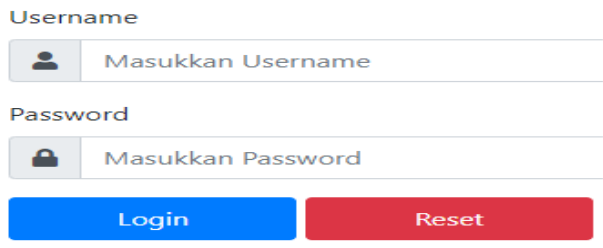

Gambar 9. Tampilan login 
JURNAL MEDIA INFORMATIKA BUDIDARMA

Volume 4, Nomor 3, Juli 2020, Page 642-649

ISSN 2614-5278 (media cetak), ISSN 2548-8368 (media online)

Available Online at https://ejurnal.stmik-budidarma.ac.id/index.php/mib

DOI 10.30865/mib.v4i3.2198

c. Halaman form input data alumni

Merupakan tampilan program untuk pendataan alumni.

\begin{tabular}{l} 
Form Pendaftaran Alumni \\
NIM: \\
Masukan Username \\
Nama: \\
Masukan Nama \\
Alamat: \\
Masukan Alamat \\
Email: \\
Masukan Email \\
No HP: \\
Masukan No HP \\
Submit \\
\hline
\end{tabular}

Gambar 10. Tampilan input data alumni

\subsection{Hasil Pengujian}

Disini penulis melakukan pengujian website menggunakan metode blackbox yaitu pengujian terhadap kebutuhan fungsi dari setiap menu pada suatu program. Pengujian metode blackbox yaitu memberikan inputan pada program, kemudian di proses sehingga menghasilkan output yang diharapkan dan sesuai kebutuhan sistem tersebut.

Tabel 1. Tabel pengujian blackbox pada form login

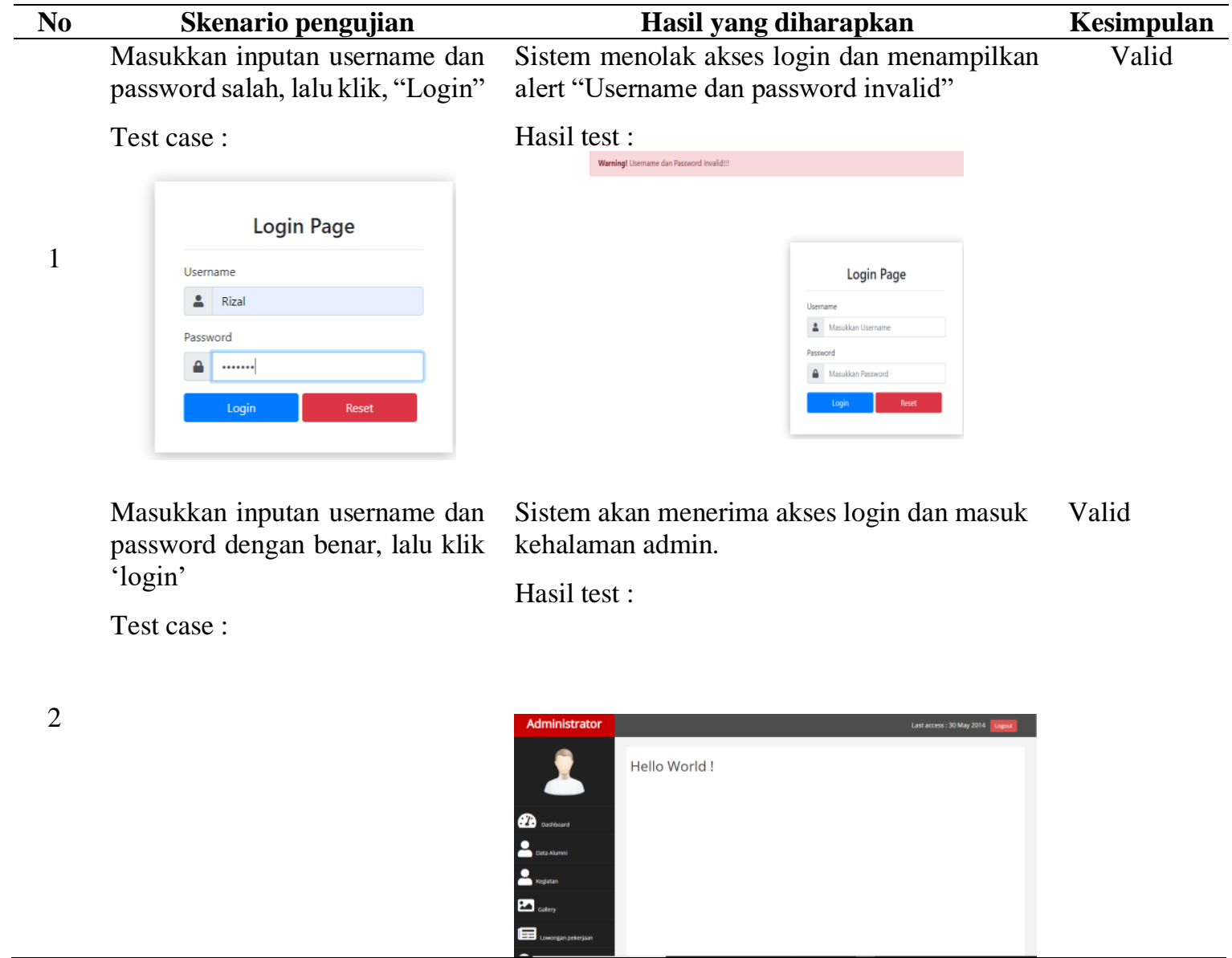




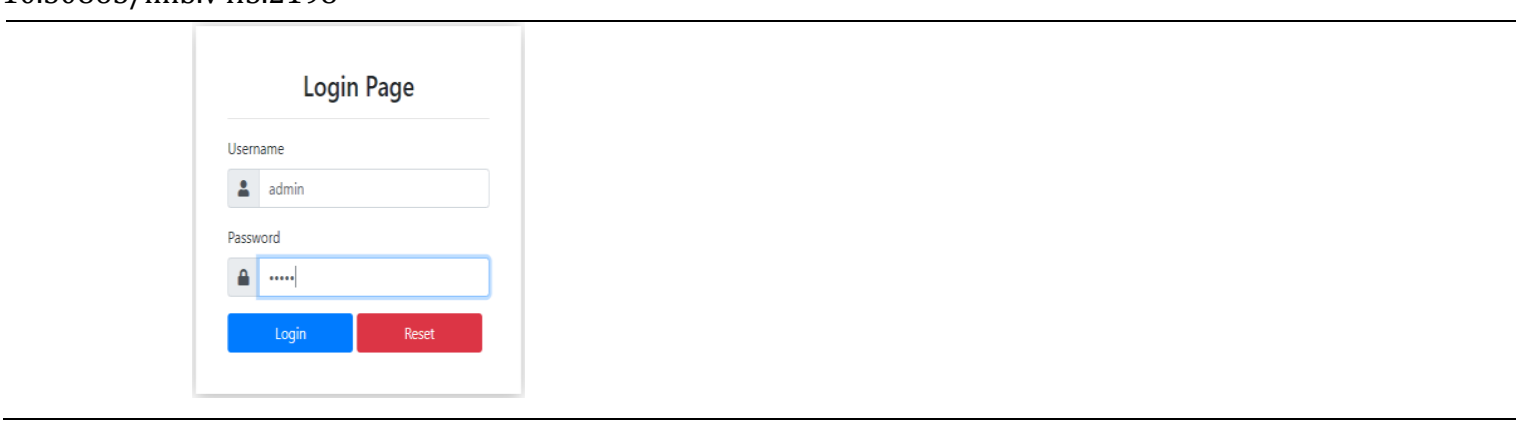

\section{KESIMPULAN}

Dari Pembahasan diatas dapat ditarik kesimpulan bahwa sistem informasi aplikasi tracer study di universitas nasional belum dilakukan secara optimal yang disebabkan kurangnya informasi pihak perguruan tinggi terhadap alumninya. Untuk mengoptimalkan apa yang terjadi, maka dari itu dibuat suatu perancangan sistem informasi aplikasi tracer study dengan desian yang baru dan memiliki fitur baru yaitu fitur lowongan pekerjaan agar alumni dapat tertarik untuk melihat fitur yang telah disediakan dan dapat digunakan dengan baik. Aplikasi ini masih bisa dikembangkan lebih lanjut dengan melakukan integrasi dengan sistem informasi akademik untuk kedepannya. Agar setiap alumni yang lulus dapat mengisi kuisioner secara langsung tanpa harus menginput data alumni terlebih dahulu apabila sistem sudah terintegrasi.

\section{REFERENCES}

[1] M. A. Maricar and Dian Pramana, "Perbandingan Akurasi Naïve Bayes dan K-Nearest Neighbor pada Klasifikasi untuk Meramalkan Status Pekerjaan Alumni ITB STIKOM Bali," J. Sist. dan Inform., vol. 14, no. 1, pp. 16-22, 2019, doi: 10.30864/jsi.v14i1.233.

[2] M. Rizka, A. Amri, H. Hendrawaty, and M. Mahdi, "Analisis Dan Perancangan Sistem Informasi Tracer Study Berbasis WEB,” J. Infomedia, vol. 3, no. 2, 2018, doi: 10.30811/jim.v3i2.716.

[3] R. M. Fajri, "Rancang Bangun Sistem Informasi Tracer Study Berbasis Web Studi Kasus Fakultas Ilmu Komputer Universitas Indo Global Mandiri," J. Ilm. Inform. Glob., vol. 7, no. 1, pp. 1-9, 2016.

[4] I. N. A. F. Setiawan and D. M. D. U. Putra, "Pengembangan Sistem Tracer Study Berbasis Web Pada STMIK STIKOM Indonesia,”S@Cies, vol. 5, no. 2, pp.118-126, 2015, doi: 10.31598/sacies.v5i2.67.

[5] R. J. Iskandar, "Perancangan Aplikasi Sistem Tracer Study Pada Stmik Widya Dharma Pontianak," vol. 4, no. 2, pp. 32 41, 2012.

[6] M. D. Ariawan, A. Triayudi, and I. D. Sholihati, "Perancangan User Interface Design dan User Experience Mobile Responsive Pada Website Perusahaan," J. Media Inform. Budidarma, vol. 4, no. 1, p. 161, 2020, doi: 10.30865/mib.v4i1.1896.

[7] C. M. C. Sakti, S. Agustin, and H. Rosyid, "Sistem Informasi Tracer Study Alumni Pada Prodi Teknik Informatika Universitas Muhammadiyah Gresik Berbasis Web," INDEXIA Infomatic Comput. Intell. J., vol. 1, no. 1, p. 22, 2019, doi: 10.30587/indexia.v1i1.822.

[8] I. Mohidin, S. Suleman, and A. Asep, "Rancang Bangun Aplikasi Tracer Study Alumni Kampus Politeknik Gorontalo Berbasis Mobile," J. Teknol. Inf. Indones., vol. 4, no. 1, pp. 18-29, 2019, doi: 10.30869/jtii.v4i1.373.

[9] L. Hakim and M. A. Oktariandi, "Perancangan Sistem Tracer Alumni Stmik Musi Rawas Berbasis Web Mobile," Jusim, vol. 2, no. 2, pp. 108-116, 2017.

[10] R. Raafi'Udin, C. Nugrahaeni Pustpita Dewi, and B. Hananto, "Perancangan Sistem Informasi Tracerstudy Menggunakan Aplikasi Open Source Di Universitas," J. Sisfokom (Sistem Inf. dan Komputer), vol. 6, no. 1, p. 33, 2017, doi: 10.32736/sisfokom.v6i1.46.

[11] Y. Andrika, M. S. Mayasari, and H. A. Pradana, "Rancangan Sistem Informasi Penelusuran Pengguna Alumni Berbasis Web The Design Of An Alumni User Tracking Information System Based On The Website," pp. 94-103.

[12] H. I. Tumenggung et al., "PERANCANGAN SISTEM INFORMASI TRACER STUDY PADA BALAI LATIHAN KERJA INDUSTRI PROVINSI BANTEN,” vol. XIV, no. 01, pp. 6-15, 2019.

[13] Y. Alvin, A. Soetrisno, A. Syakur, M. F. Amin, and M. Somantri, "Aplikasi Tracer Study Berbasis Web Pada Universitas Diponegoro," Transmisi, vol. 21, no. 4, pp. 135-146, 2019, doi: 10.14710/transmisi.21.4. 